mental quarantine stations which are studying this great question just as the State stations are studying how to cure diseases which are introduced through carelessness? Would not the investment of $\$ 50,000$ a year by the Government in such an institution, or institutions, be as paying as like amounts in State agricultural stations?

Let us have some constructive action along these lines and less antagonism. This antagonism comes from a system so manifestly inconsistent as to condemn plants to the bonfire because their breathing pores or lenticles are swollen by packing in damp moss, to let in thousands of tons of nursery stock without the slightest inspection, to allow postal shipments free entry from all parts of the world, to provide such poor facilities for control even at the best guarded ports that diseased material is left where flies and workmen come in contact with it.

The Committee on Plant and Animal Introduction therefore wishes to recommend that this most important field of research be occupied actively by the Government before the police functions of a National quarantine are forced upon it and it is obliged to hurriedly make regulations that will be needlessly severe because of an ignorance of perfectly safe methods which might be employed and prevent the necessity of prohibiting the exchange of animals and plants which is without doubt of tremendous economic importance to the country.

\title{
REPORT OF THE COMMITTEE ON BREEDING FOREST AND NUT TREES.
}

Gifford Pinchot, Washington, D. C., Chairman,

J. Russell Smith, Philadelphia, Penna., Raphael Zon, Washington, D. C., Wirlis L. Jepson, Berkeley, Calif., Geo. B. Sudworth, Washington, D. C., Geo. L. Clothier, Agricultural Col- J. W. Toomey, New Haven, Conn. lege, Miss.,

OBJecrs: To investigate and report on methods and technique of improving forest and nut trees by breeding; and to encourage the production of improved varieties of purebred forest and nut trees for each region, soil, and purpose, where they are needed.

(Report aubmitted by the Chairman.)

VARIABILITY OF FOREST TREES.

Forest trees, just as other plants or animals, are capable of producing new varieties. Darwin a says in regard to variations in forest trees: "Our forest trees, as can be learned in any botanical garden, are extremely variable. Since, however, they are not valued as highly as fruit trees, and since they bear seed late in life, no systematic methods of selection were applied to them."

a Variations of Plants and Animals II. 
There are other reasons why selection of forest trees for the purpose of producing new strains has not made the same progress as has been made with agricultural plants and domestic animals. Agricultural crops have a very short cycle of development; they are very plastic and readily made to serve the needs of man. Forest trees, on the other hand, are long-lived plants and the production of new varieties among them requires many decades or even centuries. The life of one investigator is, therefore, too short to produce any appreciable change in trees whose natural age may be from three to five hundred years. In the case even of such quickgrowing trees as black locust, catalpa, etc., a long time must elapse before the experimenter can know the outcome of his labors. To accomplish any results in breeding forest trees it is absolutely essential that there should be long-lived institutions or organizations, such as the Government Forest Experiment Stations are throughout Europe, which should carry on the experiments continuously for a long period, recording most minutely the accumulated experience. In this country, no matter how desirable such work may seem, no tangible results can be expected, unless it is undertaken by institutions which can guarantee continuity of work. For this the present organization and administration of National Forests presents admirable opportunity. It is the intention of the Forest Service of the United States Department of Agriculture to carry on, among other experimental work now planned, investigations for the improvement of useful qualities of forest trees. In one such experiment, now under way, the purpose is to study the effect of source of tree seeds on development of seedlings into timber trees. At present we have tree-sports, or half monstrosities, which spring up unexpectedly. We do not have, however, distinct races of a species which would, for instance, produce valuable heartwood earlier in life, produce wood stronger, tougher, and more resistant to decay than is produced by ordinary wild forms. The propagators of ornamental trees have succeeded in bringing forth many new forms from what, a few decades ago, were common wild forest trees. If trees vary to suit the fancy of the landscape architect, why shouldn't they be made to vary to fit the needs of the grower of wood?

\section{EFFECTS OF NATURAL AND ARTIFICIAL SEIJECTION.}

The production of new varieties of forest trees rests, as in the plant and animal world, on two fundamental biological facts: Variability and inheritance. Trees, by adapting themselves to new conditions of growth, develop variations in their form or physiological functions. These are transmitted to future generations of the same individual through the seeds or cuttings. If the same conditions prevail for a great number of generations, the newly acquired form or physiological characters become permanent and inherent in the species.

The variations in forest trees are produced in two ways: (1) By a natural selection process, and (2) by an unconscious and unsys- 
tematic, or a conscious and methodical artificial process. The natural selection goes on without human interference. It consists in eliminating individuals less adapted to certain conditions and favoring those most adapted to their environment. In natural selection, the welfare of the individual and that of the species are not antagonistic, since only such variations are preserved as are useful to the individual and give it an advantage in the struggle for existence.

Since the interference of man in the life of animals and plants, there has been going on an unconscious selection of individuals and varieties most useful to the needs of man. In this country, such unconscious selection, as regards forest trees, was practiced by the lumberman, who left the poor individuals and cut out the choicest, straightest, and soundest trees in the forest. This unconscious selection, known as "culling," has resulted, in many sections of this country, in the deterioration of forests and in the encouragement of tree weeds at the expense of the valuable and useful timber trees. This unintentional selection did not aim to produce new varieties; its purpose was merely to use the kind of trees needed, without concern as to what would happen afterwards. An unsystematic selection, which produces altogether different results, is now taking place on the National Forests, where foresters are marking trces for cutting. The forester aims to leave the proper kind of timber trees to perpetuate the forest and to check as much as possible the propagation of inferior kinds. This is, however, not the conscious methodical selection now employed in plant and animal breeding which has accomplished such wonderful results.

Methodical selection is just beginning to be recognized in forestry. It is important to bring out clearly the difference in the effect which artificial selection has upon forest trees, agricultural plants, and domestic animals. Artificial selection usually reduces the capacity of the individual to hold its own in the struggle for life. If, for instance, a full-grained variety of barley were planted in a meadow and left without cultivation, in a short time it would be entirely crowded out by the meadow grasses, because they are more easily self-sown and thrive without cultivation. The varieties produced by artificial selection require man's constant protection, and without it, are unable, as a rule, to hold their own against competitors.

With forest trees it is altogether different. The artificial selection of new varieties of forest trees must be in the direction of securing the healthiest, the most enduring, the fastest growing, and the most resistant to decay and attacks of insects or fungi-characters which are of advantage to the individual in its struggle for life as well as to the needs of man. In forestry, therefore, natural and artificial selection do not work in opposition to each other. The production of new varieties of forest trees by artificial selection is accomplished by aiding nature in the favoring of the forms best adapted to natural conditions of growth. 
RELATION OF THE SOURCE OF SEED TO THE IMPROVEMENT OF THE SPECIES.

Observations looking to such a methodical selection of desirable forest trees can be traced back to a very early date. Thus, J. Hamner more than 200 years ago observed that the heaviest seeds produced the strongest and fastest-growing seedlings. Grigor and Torres found that Scotch-pine seedlings raised from seed collected on the European continent and in Scotland behaved very differently when planted in England. Two-year-old seedlings from the continent turned brown during winter, and died in March, while seedlings from native seeds remained green and thrifty. Similar experiments with larch and fir from different sources gave relatively the same results.

Philmorin planted in the same seed-bed seeds from trees grown under different soil conditions. Although the resulting seedlings grew under precisely the same conditions, they retained the peculiar characteristics of their mother trees. Booth cites an example proving the importance also of a careful choice of seed. In sowing his seed he carried it in a small bag. In handling the bag the heavier seeds gradually settled to the bottom, while the lighter ones remained at the top. The seed-beds sown first, therefore, received the lighter seeds and produced seedlings inferior to those which were sown later and therefore received the heavier seeds taken from the bottom of the bag. Nearly all of the seedlings from the light seeds died during the second winter, while all the seedlings from the heavier seeds remained healthy.

The effect which the source of seed has upon the character of the future trees is now fully recognized by foresters. Thus, France pays $\$ 1.25$ per pound for Scotch pine seed obtained from the Riga variety for planting in her forests.

This transmission through heredity of characters acquired by trees grown under different climatic and soil conditions is to be expected. In nature, forest trees which have grown for many centuries under certain climatic and soil conditions adajted themselves to these conditions and naturally acquired characters which are transmitted by inheritance. Thus, if a spruce be taken from the plains and planted at a high elevation, it does not attain the full development it would have attained, had it been left in its original habitat. A reverse course would yield similar results. In introducing exotics from Japan and from other foreign countries, great care is now taken to ascertain the exact source of the seed, in order to insure for the introduced plants a habitat similar to that of their native home. The same care should be given to our own native trees, a precaution now only too often neglected.

These facts point out the main line of work which, in our judgment, should be undertaken if we desire to attain better results from our forests. It should consist in a careful selection, for each locality in which forests are to be grown, of seed from a locality 
with similar climatic conditions. Climate can be made a selecting agent to increase the hardiness of a species or variety. It seems to us that improvement of the so-called hardy catalpa might be effected by collecting seed for planting from trees grown as far north as this tree thrives. The same method might be applied to any other species. Professor N. E. Hansen reports that a variety of the European larch has been developed in Russia which endures much more intense cold and extreme drought than the common type. It is very desirable that this hardy sort should be introduced into the middle western prairies. By successive selections of the hardier varieties of Eucalypts, planting them gradually farther and farther northward, there may be produced new forms of Eucalypts suitable for planting much beyond its present climatic range.

Forest-tree seed should be selected with as much care as garden seed. It has not been customary in the past for forest planters to pay much attention to the source of their seed. Some evergreen growers for the ornamental trade have for many years claimed that they were able to furnish drought-resistant strains of certain conifers, because their seed is collected from trees inured to drought. It is probable that their claims are legitimate.

With the widely varying climatic conditions found on the National Forests, it would seem that the United States Government is now prepared, as no other agency on earth, to test the superiority of selected forest-tree seed in comparison with seed collected in haphazard fashion.

\section{RELATION OF THE CHARACTERS OF THE PARENT TREL TO THE SELECTION OF NEW FORMS.}

Other points, in addition to the effects of climatic range, which, I believe, should be investigated are the effect of the individual traits of the parent tree upon the seed and resulting generations of trees. These traits are age of the tree, its growth energy, its form characteristics, its general health, and the treatment it may have had during its life, such as thinming, turpentining, pruning, injury from insects, fire, fungi, etc.

Age. Observations have shown that the age of the parent tree has a great influence on future forests. It was found that the seed of very young or very old trees have a very small germinating per cent. and do not produce as strong and healthy seedlings as seed from trees which are in the period of their physical maturity.

Conditions of Growth. Trees grown in the open and trees grown in the dense forest, as a rule, bear seed which have a different germinating power and produce seedlings differing in the vigor of growth. Thus Fillipov found the following differences in the seed obtained from a tree of the same age grown in a dense stand and in the open:

The average weight of a cone from a tree grown in the forest was found to be 8.6 grammes, and the germinating per cent of its seeds, 
84 ; while the average weight of a cone from a tree grown in the open was 9.4 grammes and the germinating per cent of its seed, 96 .

Health. Regarding the effect of the parent tree's health upon the quality of seed and the vigor of seedlings, Hartig states that the inheritance of disease is unknown in the plant world. This confirms the results of investigations made up to the present time, but when one thinks of the inheritance of disease by man and other animals, a feeling that an analogy is to be found in the plant world and, therefore, a desire to carry on observations in this direction, becomes almost irresistible.

A line of investigation which promises great possibilities is the selection of trees which were left unattacked or survived the attacks of destructive forest insects, amid a stand killed by this insect. Such survivors must undoubtedly possess some inherent qualities which tend to make them immune from insect attacks. By raising trees from seed gathered from these trees, a forest might be produced which would be immune from insect attacks.

The effect of seed from dwarfed or deformed trees must by all means be investigated. Consideration of this point is of great practical importance in forestry. In carrying on lumbering operations the leaving of healthy, well-developed, merchantable trees as seed trees is always a financial sacrifice. If deformed, or dwarfed trees, which have little or no commercial value, do not transmit their individual characters, leaving these as seed trees would be a great financial gain.

Treatment of the Tree. According to experiments by Stöger a turpentining of the Austrian pine affects the quality of its seed. His conclusions are as follows:

(a) Turpentining has no apparent influence upon the germinating power.

(b) Turpentining decreases the size and weight of the seed.

(c) Turpentining decreases the vitality of the seed.

For these reasons he believes that it would be better not to use seed from turpentined trees. Similar effects follow pruning.

\section{EFFECT OF CARE AND HANULING OF SEYD ON FUTURE STOCK.}

Besides the influence of the individual characteristics of the parent trces, the handling and care of the seed from gathering to sowing, has an enormous influence on the future development of resulting trees. The drying of tree seeds, especially of conifers, influences to some extent the germinating power. In general, artificial drying always impairs, more or less, the germinating power of the seed. According to Wiesner, coniferous seed can endure, without deterioration, a temperature of $75^{\circ} \mathrm{C}$. Kientz ${ }^{b}$ found that artificial

a Centrablatt f. d. g. Forstwesen 1879, page 363.

b Einfluss der Gewinnungsart der Kiefernsamen auf die Keimfahigkeit derselben, Forstl. Bl. 1880. 
drying by fire reduces the germinating power by at least 30 per cent, as well as diminishes the germinating vigor of the seed.

The mechanical processes employed in cleaning tree seed often injures the seed cover or embryo. Gotfus, who germinated a large number of perfect and injured seeds, found that injured seeds invariably have a smaller germinating per cent.

The germinating per cent of coniferous seeds depends upon the presence or absence of their wings. Thus, for example, spruce seeds with wings have a germinating per cent of 60 , while spruce seeds without wings having a germinating per cent of only 50 ; larch has 40 and 35 respectively; fir, 50 and 40 ; Scotch pine, 60 and 50 per cent.

\section{SELECTION OF SEEDLINGS FOR PLANTING AND FOR THINNING.}

Following the proper selection of seed must come the selection of seedlings when they are taken from the seed-bed for permanent planting. Only seedlings with every indication that they will develop into valuable timber trees should be selected for planting. All seedlings of inferior character, especially those which have been attacked by insects or fungous disease should be discarded.

Further and more thorough selection should be made when the stand is thinned. In this operation all trees showing inferior development must be taken out, thus preventing them from propagating themselves and in this way transmitting undesirable characters. Only the most vigorous, the soundest, and best developed trees should be allowed to perpetuate the forest or to supply seed for new plantations.

\section{GRAFTING AND BUDUING.}

Although grafting and budding answer better the needs of the horticulturist than those of the forester, for propagating desirable individuals, nevertheless, these methods possess great possibilities for the forester also. The chief aim of the forester is to produce the largest quantity of wood in a given uime. Since, we know that it is possible to increase the growth of a slow-growing tree by grafting a fast-growing scion upon it, it would seem that a slow-growing species like shag-bark hickory might be grafted on such a fastgrowing stock as walnut or pecan, and the growth of the hickory be thus considerably accelerated. Should this be feasible; then it may be possible to similarly hasten the growth of white oak by grafting it on the faster growing red oak. In the North Central States suitable timber for fence posts is very scarce. A small native willow known as the "diamond willow", growing in the valley of the Upper Missouri, produces very durable wood, but seldom grows large enough for posts. If by grafting the "diamond willow" upon the cottonwood, it can be made to grow fast enough and large enough for fence posts, a great problem to the farmers of the Red River Valley of the North 
will have been solved. Mr. E. F. Kirkpatrick of McKinney, Texas, suggested that grafting or budding might be utilized for the increase of such varieties as curly walnut, "birdseye," curly maple, etc.

SUMMARY.

The present status of producing new varieties of forest trees and the most urgent problems connected with it may be formulated as follows:

1. The need and the possibility of a methodical selection of forest stock cannot be denied.

2. Our knowledge of biological facts upon which to base a methodical selection of forest trees is still very meager. Therefore, untiring and energetic efforts to increase it are most urgently required.

3. The most suitable institutions for work of this kind are forest experiment stations. In the United States, where there are no forest experiment stations, this work should be undertaken by the existing agricultural experiment stations as a distinct forest work. This work should also be carried on by the Forest Service on the National Forests.

4. The selection must begin with the proper choice of the source of seed. For every species and for every region there should be selected only such seeds as are gathered from trees grown under conditions essentially similar to those in which the seeds are to be planted.

5. Experiments are needed to determine the influence of individual characters of the parent tree, such as its age, its health, its growth energy, its form, and the treatment it may have had during its life.

6. The selection must also consider the qualities of the seed, such as weight, germinating per cent., and the vigor of germination.

7. The selection should be extended also to seedlings at the time of permanent planting, and to stands when they are to be thinned.

8. Experiments in grafting and budding should be made to determine the possibilities of producing new varieties possessing more desirable qualities than either parent stock.

\title{
BREEDING FOREST TREES FOR SEMI=ARID CALIFORNIA- PROPOSED CROSSES AND SELECTIONS.
}

\author{
By Wiluis Linn JePson, Berkeley, Calif. \\ (Member of Committee on Breeding Forest and Nut Trees.)
}

The semi-arid foothill area in California surrounding the valley plain comprises about 10,000 square miles. This is exclusive of chaparral and yellow pine areas. The altitude varies from 500 to 3,000 feet at the south, and from 100 to 1,500 feet at the north. The average rainfall is 10 to 20 inches, the minimum toward the 